\title{
Optimal Option Ordering Strategies for Capital-Constraint Retailers Based on CVaR
}

\author{
Dan-feng WANG ${ }^{1,}$, Wen-sheng YANG $^{1, b}$ \\ ${ }^{1}$ School of Economics and Management, Nanjing University of Science and Technology, China \\ aemail:1528378385@qq.com, bemail:wensheng_yang@163.com
}

\begin{abstract}
Keywords: Supply chain, CVaR, Option contract, Capital constraint, Ordering strategies.
Abstract. For a two-stage supply chain system which consists of a supplier and a retailer with capital constraint, the supplier provides the retailer with option contract. By establishing the ordering model under option contract for the retailer with capital constraint based on CVaR, the optimal order of retailers with different risk aversion is derived. The order changes of retailers under different risk aversion are analyzed, and the impacts of contract parameters and interest rate on optimal decisions are discussed. The results show that the optimal fixed order quantity and option order quantity of retailers are related to the degree of risk aversion, interest rate and retailer's capital on hand and contract parameters. At last, numerical examples are provided to demonstrate the results.
\end{abstract}

\section{Introduction}

With the development of customer's demand for personalized and diversification, the uncertainty of market demand is more obvious. Besides, companies in the real operating are faced with funding constraints. The retailer with capital constraints will consider how to optimize their operational decisions by external financing and control the risk more effectively.

In option contract, buyers can exercise all or part of the option according to the actual demand. For example, Hewlett-Packard will use $35 \%$ of the purchasing cost to purchase options. With the coming of selling season, HP can exercise option contracts. In this way, they can complete procurement with lower purchasing cost. Every enterprise's risk preferences are different. Conditional Value at Risk $(C V a R)$ model is a tool which can help enterprises achieve the greatest profits at a certain level of risk. In order to control the risk effectively, retailers can use $C V a R$ model to optimize order decisions.

Ritchken [1] combines option with the traditional order mode earliest and find it can improve the flexibility of supply chain. Fu [2] studies the optimal combination of procurement strategy by assuming retailers can use fixed price contracts and option contracts or the spot market to purchase. Lee and Liu [3,4] show the optimal decision by combining option contracts with spot market or quantity discount contract. Sun [5] considers agricultural market with random demand and information updated.

Chen [6] discusses the optimal purchasing decisions while retailers can obtain financing from the capital markets. Zhong [7] discusses the pricing and ordering problem when retailers use credit support from manufacturer. Yi [8] investigates when retailers with capital constraint will give up option contracts. Cai [9] compares retailers' decision under bank credit and trade credit. Chen [10] find credit financing can make the revenue of supply chain higher.

$\mathrm{Mu}$ [11] builds the option model in case of risk aversion. Study shows that the higher of risk aversion, the lower of the amount of option order. Ma[12] uses Nash equilibrium to discuss wholesale price and order quantity under $C V a R$.

For retailer's purchasing decisions with capital constraint, we hope to combine option contracts with $C V a R$ to optimize order decisions and control risk.

\section{Model descriptions and assumptions}

In this paper, there is a two-stage supply chain with a supplier and a retailer with capital constraint. The retailer is risk aversion. Retailer and the supplier sign a contract with option. Before the selling 
season, the retailer decides the fixed order $Q$ at the wholesale price of $w$ per unit. In addition, the retailer purchases $q$ options at the price of $w_{0}$ per unit. At the beginning of the sales season, the fixed order is delivered. The retailer can exercise option at the exercise price of $w_{e}$ per unit. The number of option retailer exercise is lower than $q$.The retailer has limited budget of $Y$, When the retailer with capital constraint making order decisions, it can borrow money from the bank with interest rate $r$.The $f(x)$ is the probability density function and $F(x)$ is its cumulative distribution function.

According to Ritchken [1] $\operatorname{CVaR}_{\beta} \pi(\varepsilon)=\max _{v_{0} \in R}\left\{v_{0}+\frac{1}{\beta} \mathrm{E}\left[\left(\pi(\varepsilon)-v_{0}\right)^{-}\right]\right\}, \beta$ is retailer's attitude towards risk. Our objective function is $\max _{Q, q \geq 0} C \operatorname{VaR}_{\beta}(Q, q) . \beta=1$ means that retailers are risk-neutral. Define $G(Q, q)=C \operatorname{VaR}_{\beta} \pi(\varepsilon)$

\section{Retailer's option ordering model based on $C V a R$}

Retailer's expected profit function is

$$
\begin{aligned}
\pi(Q, q) & =\int_{0}^{Q}\left\{p x-w Q-w_{0} q-r\left[w Q+\left(w_{0}+w_{e}\right) q-Y\right]\right\} f(x) d x \\
& +\int_{Q}^{Q+q}\left\{p x-w_{e}(x-Q)-w Q-w_{0} q-r\left[w Q+\left(w_{0}+w_{e}\right) q-Y\right]\right\} f(x) d x \\
& +\int_{Q+q}^{+\infty}\left\{(p-w) Q+\left(p-w_{0}-w_{e}\right) q-r\left[w Q+\left(w_{0}+w_{e}\right) q-Y\right]\right\} f(x) d x
\end{aligned}
$$

When $-w Q-w_{0} q-r\left[w Q+\left(w_{0}+w_{e}\right) q-Y\right] \leq v_{0}<p Q-w Q-w_{0} q-r\left[w Q+\left(w_{0}+w_{e}\right) q-Y\right]$

$$
G(Q, q)=p F^{-1}(\beta)-w Q-w_{0} q-r\left[w Q+\left(w_{0}+w_{e}\right) q-Y\right]-\frac{p}{\beta} \int_{0}^{F^{-1}(\beta)} F(x) d x
$$

Due to $\frac{\partial G(Q, q)}{\partial Q}<0$ and $\frac{\partial G(Q, q)}{\partial q}<0$, there is no optimal solution.

When

$$
\begin{gathered}
p Q-w Q-w_{0} q-r\left[w Q+\left(w_{0}+w_{e}\right) q-Y\right] \leq v_{0}<(p-w) Q+\left(p-w_{0}-w_{e}\right) q-r\left[w Q+\left(w_{0}+w_{e}\right) q-Y\right] \\
G(Q, q)=\left(p-w_{e}\right) F^{-1}(\beta)-w Q-w_{0} q-r\left[w Q+\left(w_{0}+w_{e}\right) q-Y\right]+w_{e} Q \\
\quad-\frac{p}{\beta} \int_{0}^{Q} F(x) d x-\frac{p-w_{e}}{\beta} \int_{Q}^{F^{-1}(\beta)} F(x) d x
\end{gathered}
$$

Due to $\frac{\partial G(Q, q)}{\partial q}=-w_{0}-r\left(w_{0}+w_{e}\right)<0$, there is no optimal solution.

When $v_{0} \geq(p-w) Q+\left(p-w_{0}-w_{e}\right) q-r\left[w Q+\left(w_{0}+w_{e}\right) q-Y\right]$

$G(Q, q)=(p-w) Q+\left(p-w_{0}-w_{e}\right) q-r\left[w Q+\left(w_{0}+w_{e}\right) q-Y\right]-\frac{p}{\beta} \int_{0}^{Q+q} F(x) d x+\frac{w_{e}}{\beta} \int_{Q}^{Q+q} F(x) d x(4)$

With the $\max G(Q, q)$ as the goal,if $\frac{\partial G(Q, q)}{\partial Q}=0, \frac{\partial G(Q, q)}{\partial q}=0$, the optimal order strategy can be described as table 1. While $\frac{\left[p-(1+r)\left(w_{0}+w_{e}\right)\right]}{p-w_{e}} \leq \frac{(1+r)\left(w_{0}+w_{e}-w\right)}{w_{e}}, Q_{0}{ }^{*}=Q^{*}, Q_{0}{ }^{*}$ means the optimal order quantity under the wholesale price contract.

Proposition: With the same risk aversion, the optimal order quantity under wholesale price contract is less than the total quantity of the fixed order and option under option contracts, but it is more than the fixer order under option contracts, $Q^{*}<Q_{0}^{*}<Q^{*}+q^{*}$. 
Proof $F\left(Q^{*}+q^{*}\right)-F\left(Q_{0}^{*}\right)=\beta \frac{p w_{e}-p(1+r)\left(w_{0}+w_{e}\right)+p w(1+r)-w w_{e}(1+r)}{\left(p-w_{e}\right) p}$

Due to $p w_{e}-p(1+r)\left(w_{0}+w_{e}\right)+p w(1+r)-w w_{e}(1+r)$, besides $p-w_{e}>0$, so $F\left(Q^{*}+q^{*}\right)-F\left(Q_{0}^{*}\right)>0$. Similarly, $F\left(Q^{*}\right)<F\left(Q_{0}^{*}\right)$.

Table 1 .Optimal ordering strategy

\begin{tabular}{|l|l|l|}
\hline$\frac{\left[p-(1+r)\left(w_{0}+w_{e}\right)\right]}{p-w_{e}}>\frac{(1+r)\left(w_{0}+w_{e}-w\right)}{w_{e}}$ & $F^{-1}\left[\frac{\beta(1+r)\left(w_{0}+w_{e}-w\right)}{w_{e}}\right]$ & $F^{-1}\left\{\beta \frac{\left[p-(1+r)\left(w_{0}+w_{e}\right)\right]}{p-w_{e}}\right\}$ \\
\hline$\frac{\left[p-(1+r)\left(w_{0}+w_{e}\right)\right]}{p-w_{e}} \leq \frac{(1+r)\left(w_{0}+w_{e}-w\right)}{w_{e}}$ & $F^{-1}\left[\frac{\beta(p-w-r w)}{p}\right]$ & 0 \\
\hline
\end{tabular}

\section{Numerical Studies}

To describe our analysis, we design the following numerical study. The demand is assumed to be an exponential distribution with $\lambda=0.01 . p=12, w=7, w_{0}=1, w_{e}=8, r=2 \%, Y=20$.
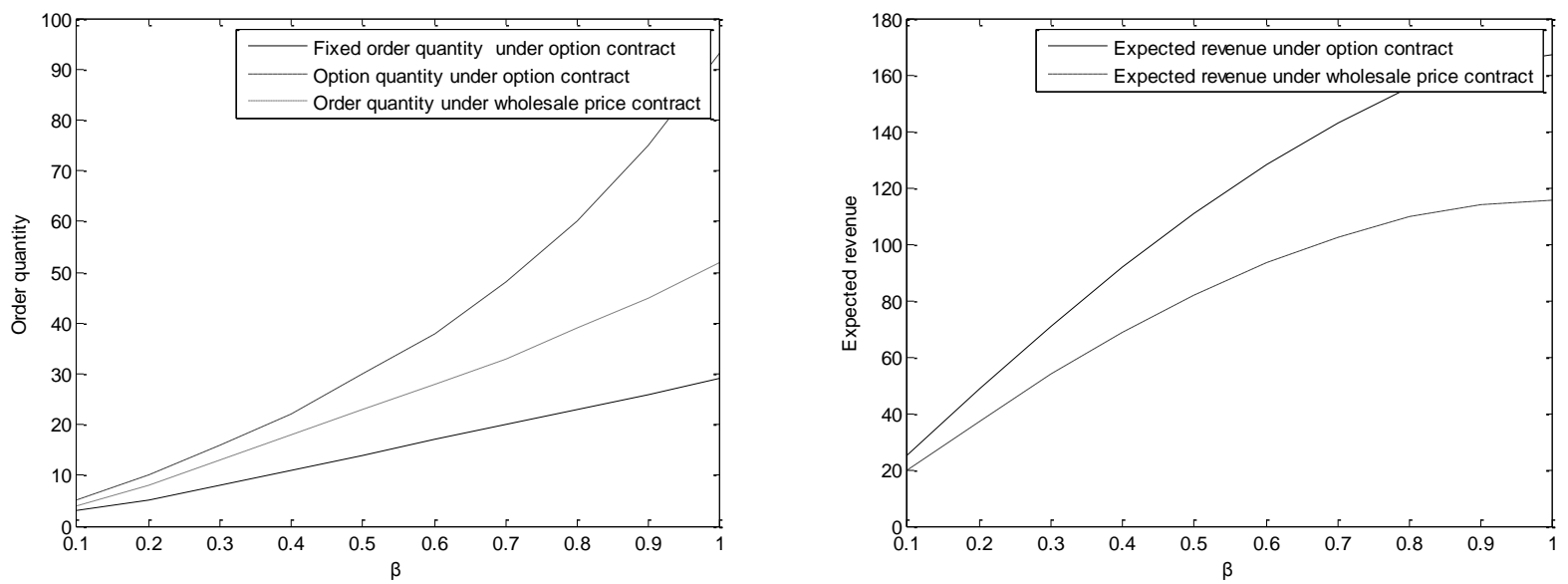

Fig.1 Retailer's ordering strategy and expected revenue

We examine the impacts of $\beta$ on the optimal ordering strategy and the expected revenue of the retailer. We can draw that along with the increase of $\beta$, the retailer's optimal fixed order and option order under option contracts and the optimal order quantity under wholesale price contracts are on the increase as Fig. 1. Besides, the retailer's expected revenue are increased in both contracts. The change trade is mainly due to the increase of $\beta$, which means the retailer becomes risk-neutral and takes on more risk. Option contract brings more revenue than wholesale price contract. In addition, the advantage is more and more obvious with the increase of $\beta$.

Under the same $\beta$, fixed order is on the increase and the option order reduces with the increase of $r$ as table.2. The increase of $r$ adds the cost of financing. Since the purchase cost of option is higher than the wholesale price, the retailer prefers to purchase more fixed order and less option. Option contract brings more revenue than wholesale price contract. Besides, the advantage is smaller with the increase of $r$ as Fig.2. That means if loan interest rate is high, the attraction of option contract will be reduced. 
Table2. Optimal ordering strategy with different interest rate

\begin{tabular}{|l|l|l|l|}
\hline & Q & q & Q + q \\
\hline$r=0.02$ & 23 & 60 & 83 \\
\hline$r=0.11$ & 25 & 26 & 51 \\
\hline$r=0.17$ & 27 & 8 & 35 \\
\hline
\end{tabular}

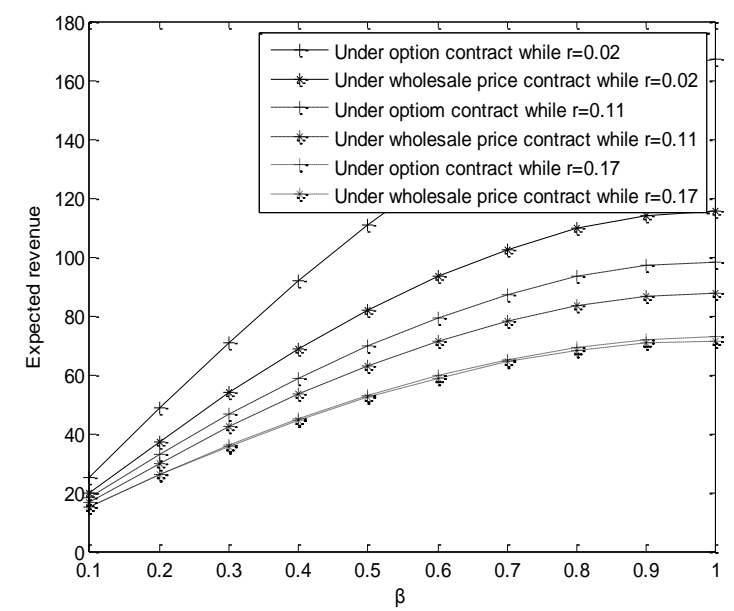

Fig.2 Retailer's expected revenue with different interest rate

\section{Conclusion}

This paper investigates the optimal ordering strategy for the retailer with capital constraint. We find that the optimal fixed order and option order are related to retailer's attitude to risk and the loan interest rate. When the loan interest rate is increasing, the retailer's optimal decision is to order more fixed order and less option. There is a critical point whether the retailer to accept the option contract. Further studies can be extended to other supply chain financing modes.

\section{Acknowledgement}

This paper is supported by research grants from the Research Fund for the Doctoral Program of Higher Education of China(Grant No.20133219110033) and Humanities and Social Sciences of Ministry of Education Planning Fund of China(Grant No.15YJA630087).

\section{References}

[1] P. H .Ritchken, C .S.Tapiero: Operations Research Vol.34(1986), p. 864-870.

[2] Q. Fu, C.Y Lee and C. P.Teo: IIE transactions Vol. 42(2010), p. 793-811.

[3] C. Y. Lee, X. Li and Y. Xie: IIE transactions Vol.45(2013), p. 845-864.

[4] Z. Liu, L. Chen and L. Li: International Journal of Production Economics Vol. 151(2014), p.112-120.

[5] G.H.Sun, L.Xu: Journal of Management Engineering Vol. 2 (2014), p. 201-210.

[6] X.F.Chen,D.L.Zhu and W.J.Yin: Journal of Management Science Vol. 11(2008), p. 70-77.

[7] Y.G.Zhong,Y.W.Zhou and B.X.Li: Journal of Management Science Vol. 14(2011), p. 57-67.

[8] Y. Feng, Y. Mu and B. Hu: International Journal of Production Economics Vol. 153(2014), p. 230-237.

[9] G. Cai, X. Chen and Z. Xiao: Production \& Operations Management Vol. 23(2012), p. 583-598.

[10] X. Chen: International Journal of Production Economics Vol. 159(2015), p. 347-357.

[11] Y.G.Mu,Q.Mai and Y.J.Feng: China Soft Science Magazine Vol.S1 (2009), p. 252-257.

[12] L. Ma, F. Liu and S. Li: International Journal of Production Economics Vol. 139(2012), p. 155-167. 